\title{
Does Celiac Disease Effect Electrocardiographic Markers of Arrhythmic Events in Children?
}

\author{
(1) Tülay Demircan1, (1) Yeliz Çağan Appak2, (1) Maşallah Baran³, (1) Betül Aksoy2, (1) Barış Güven1, \\ (D) Nazmi Narin 4 , (1) Cem Karadeniz4 \\ 1University of Health Sciences Turkey, İzmir Tepecik Training and Research Hospital, Clinic of Pediatric Cardiology, İzmir, Turkey \\ 2University of Health Sciences Turkey, İzmir Tepecik Training and Research Hospital, Clinic of Pediatric Gastroenterology, İzmir, Turkey \\ 3izmir Katip Çelebi University Faculty of Medicine, Department of Pediatric Gastroenterology, Izmir, Turkey \\ ${ }^{4}$ Izmir Katip Çelebi University Faculty of Medicine, Department of Pediatric Cardiology, İzmir, Turkey
}

\begin{abstract}
Aim: Cardiac abnormalities associated with celiac disease (CD) have been reported. However, changes in electrocardiographic (ECG) parameters in children with CD have not been previously evaluated in the literature. In this study, we aimed to evaluate these parameters which may be determinative in the development of atrial and ventricular arrhythmia of children with CD.

Materials and Methods: Patients diagnosed with CD in the gastroenterology clinic were included in the study. ECG measurements of QT, T peak to end (Tp-e) and P intervals were performed. The Tp-e/QT ratio was calculated from these measurements. Echocardiographic and ECG parameters of the patients and controls were compared. Those patients with elevated anti-tissue transglutaminase immunoglobulin A (IgAtTG) levels were considered positive serology. The patients were divided in three groups and compared with each other according to ECG parameters; namely newly diagnosed patients, patients with seropositive and patients with seronegative who had been on a gluten free diet for at least 6 months.

Results: Fifty-two patients with CD and 59 healthy volunteers were included. P-wave dispersion, QTd, corrected QT dispersion (QTcd), Tp-e dispersion and TP-e/QT ratio were higher in those children with CD compared to the controls. We did not find any correlation between IgA-tTC levels and P-wave, QT and Tp-e dispersions. There was no difference between the three groups of CD patients for ECG and echocardiographic parameters.

Conclusion: CD is associated with changes in some ECG parameters, which are considered as predictors of atrial and ventricular arrhythmias in special populations. For this reason, children with CD should be evaluated in terms of these parameters, and more electrophysiological studies are necessary to reveal the clinical and prognostic effects of these parameters for CD.
\end{abstract}

Keywords: Electrocardiography, celiac disease, Tp-e dispersion, Tp-e/QT ratio, ventricular depolarization, arrhythmias

\section{Introduction}

Celiac disease (CD) is a chronic immune-mediated disease triggered by gluten, which often results in diffuse inflammatory damage to the small intestinal mucosa (1). Gluten, found in wheat, barley and rye, has this effect only on genetically predisposed people through the interaction of environmental and immunological factors (2). The frequency of CD varies with respect to geographical regions, and different studies report that its prevalence varies between $0.8 \%$ and $1 \%(3,4)$. In Turkey, this prevalence

\section{Address for Correspondence}

Tülay Demircan MD, University of Health Sciences Turkey, İzmir Tepecik Training and Research Hospital, Clinic of Pediatric Cardiology, izmir, Turkey Phone: +90 5057538760 E-mail: tulay.sirin@hotmail.com ORCID: orcid.org/0000-0002-2529-2906 Received: 11.12 .2019 Accepted: 02.03 .2020

${ }^{(0)}$ Copyright 2021 by Ege University Faculty of Medicine, Department of Pediatrics and Ege Children's Foundation The Journal of Pediatric Research, published by Galenos Publishing House. 
is reported to be 1 in 212 (5). A gluten-free diet is the current treatment for CD (1).

Various cardiovascular abnormalities such as cardiomyopathy, myocarditis, arrhythmias, and premature atherosclerosis have been reported in adult populations with CD (6). Few studies have studied cardiovascular involvement in children with CD, with most of them focusing on clinical and subclinical left ventricular dysfunction (7). Some electrocardiographic (ECG) changes such as P-wave dispersion (PWd), QT dispersion (QTd) and T peak to end (Tp-e) interval, which is the measurement of the interval between the peak and the end of the T-wave, Tp-e/QT ratio and Tp-e dispersion have emerged as markers of transmural dispersion of repolarization (TDR) and it has been reported that they can predict the development of atrial and ventricular arrhythmias $(8,9)$. Although some adult studies have reported on CD patients, these ECG parameters have not been evaluated in children with CD before $(10,11)$. Therefore, we aimed to evaluate PWd, QTd, Tp-e interval and dispersion and Tp-e/QT ratio in children with CD.

\section{Materials and Methods}

In this prospective study, those patients with CD admitted to a pediatric gastroenterology outpatient clinic between March 2018-August 2018 were included. The research procedure was approved by the Local Ethics Committee (no: 2018/3-9). The patients signed consent forms which gave information concerning the purpose of this study. Those patients whose celiac serology were positive, who had undergone upper gastrointestinal system endoscopy, and whose duodenum and bulbous specimens were taken and histologically diagnosed as CD were included in this study. CD patients were defined according to the European Society for Pediatric Gastroenterology and Hepatology and Nutrition criteria (12). Healthy volunteers of the same age and gender were included as a control group. These individuals were referred to a pediatric cardiology outpatient clinical for cardiac evaluation due to murmurs but had no structural heart disease detected with echocardiographic examination. CD patients and healthy volunteers with known structural and/or valvular congenital heart disease, thyroid dysfunction or additional chronic disease or those taking any medication that could affect heart rate and ECG parameters were excluded from the study. The patients' clinical and demographic data was determined. Anthropometric measurements of weight, height, and body mass index were obtained.

Echocardiographic examination was performed by a single pediatric cardiologist using the Philips Ultrasound
System and S 3-1 probe. Conventional echocardiographic measurements were made in accordance with the standards of the American Echocardiography Association (13). The dimensions of the left ventricle in the parasternal long axis on $\mathrm{M}$ mode tracing, and ejection fraction (EF) and fractional shortening were analyzed using the Teichholz formula (14).

ECG measurements of QT, Tp-e and P intervals were performed by a pediatric cardiologist who was blind to patient data. The TP-e interval, QT interval, and P-wave interval were obtained from a minimum of six measurements, at least three of which were from precordial leads. The QT interval was measured from the beginning of the QRS complex to the end of the T-wave and corrected for heart rate according to Bazett's formula (15). The Tp-e interval was defined as the interval from the peak of the T-wave to the end of the T-wave. Measurements of the Tp-e interval were performed from precordial leads (16). The Tp-e/QT ratio was calculated from these measurements. P-wave interval was measured from the beginning of the P-wave to the end of the P-wave. Echocardiographic and ECG parameters of the patients and controls were compared. The patients were divided into three group and compared with each other according to ECG parameters; namely newly diagnosed patients, patients with seropositive and patients with seronegative who had been on a gluten free diet for at least 6 months. Patients with elevated anti-tissue transglutaminase IgA (IgA-tTG) levels were considered positive for celiac serology.

\section{Statistical Analysis}

G* Power 3.1 program was used to determine the sample size. In this study, the sample size was determined as follows; patients and the controls to be in a 1-1 ratio, at least 128 patients comprising 64 patients in each group with medium effect size of 0.5 , a type-1 error of $5 \%$ and the type2 error of $20 \%$ and with $80 \%$ power, which was suggested by Cohen (17) in the literature. In this study, a total of 111 individuals, 52 of them being celiac and the remaining being healthy controls who were admitted to our hospital during a 6-months period were enrolled. Accordingly, for QTd values with the use of mean + standard deviation between those patients with celiac and the controls, the effect size was calculated as $d=2$. At the end of the study, the power of the test was calculated to be $99.9 \%$.

Data were analyzed using the IBM SPSS Statistics 25.0 (IBM Corp., Armonk, New York, USA) statistical package program. Normal distribution of continuous variables was evaluated by Shapiro-Wilk normality test and Q-Q graphs. Whether the group variances were homogeneously distributed or not was examined by Levene test. For the 
normal distribution of continuous variables, the t-test for parametric statistical tests was used to compare the two groups, and One-Way ANOVA was used to compare more than two groups. Median (Q1-Q3) values were given as descriptive statistics in the analysis of variables with non-normal distribution. In the comparison of the two groups, the non-parametric statistical test Mann-Whitney $U$ and in the comparison of more than two groups, the Kruskal-Wallis $\mathrm{H}$ test were used. Relationships between variables were evaluated by Spearman correlation analysis. The relationships between variables with categorical structure were evaluated by using the Continuity Correction chi-square test in $2 \times 2$ tables. $\mathrm{P}<0.05$ was considered as statistically significant (17).

\section{Results}

Fifty-two patients with CD and 59 healthy volunteers were included in this study. The baseline clinical characteristics of the patients and controls are shown in Table I. The mean age of the CD patients was $10.24 \pm 4.6$ years and $58.8 \%$ were female. There were no difference in terms of age and gender $(p=0.025)$. The laboratory parameters of CD patients are shown in Table II. The mean follow-up period of CD patients was $29.8 \pm 28.4$ months.

The ECG and echocardiographic findings of the patient and control groups are given in Table III. There was no significant difference in left ventricular dimensions and EF between groups. PWd, QTd, corrected QTcd, Tp-e dispersion and TP-e/QT ratio were higher in children with CD compared to the controls. We did not find any correlation between IgAtTG levels and P-wave, QT and Tp-e dispersions ( $p=0.95,0.67$,
0.97 respectively). When the ECG and echocardiographic parameters of CD patients were compared with each other, we did not find any difference between groups (Table IV). QT and QTcd was found to be significantly higher in seronegative patients who were under celiac diet compared to the controls $(p<0.05)$.

\section{Discussion}

In the current study, we have investigated atrial and ventricular depolarization together with ventricular repolarization changes in children with $C D$. We found that the P-wave, QT and QTc dispersions, Tp-e dispersion and Tp-e/QT ratio were prolonged in patients with CD. However, we did not find any difference in Tp-e/QTc ratios between the groups and we did not find any correlation between IgAtTC and PWd, QTd, QTc d and Tp-e dispersion.

Different types of cardiovascular diseases in CD such as autoimmune myocarditis, left ventricular dysfunction, congestive heart failure and arrhythmia have been described $(6,7)$. Antibodies specific for CD have been observed in some patients with autoimmune myocarditis (18). Some research revealed subclinical left ventricular systolic dysfunction by using conventional and strain echocardiography in children and adults with CD $(19,20)$. Some theories have been proposed to explain the mechanisms of cardiac involvement in these patients. One of these theories is that nutritional deficiency is triggered by intestinal malabsorption and another is autoimmune is triggered myocardial involvement (20). In our study, although we did not find any systolic dysfunction by using conventional M-mode echocardiography, we think that further studies

\begin{tabular}{|c|c|c|c|}
\hline & $\begin{array}{l}\text { Patient group mean } \pm \text { SD } \\
M(Q 1-Q 3)\end{array}$ & $\begin{array}{l}\text { Control group mean } \pm S D \\
M(Q 1-Q 3)\end{array}$ & $\mathbf{p}$ \\
\hline Age (year) & $\begin{array}{l}10.24 \pm 4.63 \\
10(6.25-14.75)\end{array}$ & $\begin{array}{l}10.47 \pm 4.28 \\
11(7-14)\end{array}$ & $0.143+$ \\
\hline \multicolumn{4}{|l|}{ Gender } \\
\hline Girl (n, \%) & $31(59.6)$ & $28(47.5)$ & \multirow{2}{*}{$0.318^{*}$} \\
\hline Boy $(n, \%)$ & $21(40.4)$ & $31(52.5)$ & \\
\hline Body mass index $\left(\mathrm{kg} / \mathrm{m}^{2}\right)$ & $\begin{array}{l}17.42 \pm 3.44 \\
16.59(14.38-19.54)\end{array}$ & $\begin{array}{l}23.20 \pm 39.69 \\
17.85(15.43-20.77)\end{array}$ & $0.124+$ \\
\hline Heart rate (bpm) & $\begin{array}{l}112.37 \pm 129.47 \\
90(80-114)\end{array}$ & $\begin{array}{l}89.45 \pm 16.59 \\
89.50(76-102.25)\end{array}$ & $0.201+$ \\
\hline Mean sistolic blood pressure (mmHg) & $\begin{array}{l}106.91 \pm 15.45 \\
109(100-120)\end{array}$ & $\begin{array}{l}113.21 \pm 11.57 \\
113.50(106.50-120)\end{array}$ & $0.082+$ \\
\hline Mean diastolic blood pressure $(\mathrm{mmHg})$ & $\begin{array}{l}63.66 \pm 8.78 \\
60(60-70)\end{array}$ & $\begin{array}{l}62.71 \pm 9.65 \\
60(60-70)\end{array}$ & $0.441+$ \\
\hline
\end{tabular}




\begin{tabular}{|c|c|c|}
\hline & Mean \pm SD M (Q1-Q3) & Minimum-Maximum \\
\hline Hemoglobin (g/dL) & $\begin{array}{l}12.57 \pm 1.46 \\
12(11.6-13.2)\end{array}$ & $8.6-16.2$ \\
\hline WBC (cell/mm³) & $\begin{array}{l}7,750 \pm 1,797 \\
7,900(6,500-9,100)\end{array}$ & $4,900-12,200$ \\
\hline Platelet (cell/mm³) & $\begin{array}{l}299,780 \pm 74,486 \\
303,000(255,000-366,000)\end{array}$ & $158,000-487,000$ \\
\hline AST (IU/L) & $\begin{array}{l}29.4 \pm 9.7 \\
31(23-36.5)\end{array}$ & $10-57$ \\
\hline ALT (IU/L) & $\begin{array}{l}17.6 \pm 9.5 \\
16(11-20)\end{array}$ & $6-58$ \\
\hline Ure $(\mathrm{mg} / \mathrm{dL})$ & $\begin{array}{l}20.8 \pm 6.8 \\
19(14.5-22.5)\end{array}$ & $10-36$ \\
\hline Creatinine (mg/dL) & $\begin{array}{l}0.57 \pm 0.12 \\
0.5(0.45-0.6)\end{array}$ & $0.3-0.9$ \\
\hline Sodium (mEq/L) & $\begin{array}{l}139 \pm 2 \\
139(137-141.5)\end{array}$ & $134-144$ \\
\hline Potassium (mmol/L) & $\begin{array}{l}4.3 \pm 0.37 \\
4.2(4-4.55) \\
\end{array}$ & $3.5-5.6$ \\
\hline Calcium (mg/dL) & $\begin{array}{l}9.9 \pm 0.3 \\
9.9(9.6-10) \\
\end{array}$ & $9.2-10.7$ \\
\hline Albumin (gr/dL) & $\begin{array}{l}4.39 \pm 0.28 \\
4.3(4.3-4.55)\end{array}$ & $3.5-5.1$ \\
\hline Ferritin $(\mathrm{ng} / \mathrm{mL})$ & $\begin{array}{l}25.6 \pm 16.6 \\
23(13.5-44) \\
\end{array}$ & $2-70$ \\
\hline Folic acid (ng/mL) & $\begin{array}{l}12.4 \pm 5.1 \\
13(8.5-17.85)\end{array}$ & $5-24$ \\
\hline Vitamin D (ng/mL) & $\begin{array}{l}20.4 \pm 9.57 \\
20(11-29.7) \\
\end{array}$ & $6-50$ \\
\hline IgA-tTG (RU/mL) & $\begin{array}{l}105 \pm 82 \\
200(58-200)\end{array}$ & $0-200$ \\
\hline
\end{tabular}

with strain echocardiography with larger numbers of patients are needed to demonstrate the subclinical left ventricular dysfunction in children with $C D$.

Recent studies have shown that PWd is an ECG marker which reflects the homogenous distribution of atrial conduction. Its predictive value has been shown in different clinical situations such as atrial flutter and fibrillation in patients with CD (16). Inflammation may trigger fibrosis and structural changes that results in arrhythmogenic substrate for atrial fibrillation in CD patients. In a study, Karadeniz et al. (21) showed prolonged P-wave duration and dispersion in children with low iron stores. Secondary iron deficiency anemia is more common in CD patients due to malabsorption. Although we did not study the correlation between ferritin level and PWd in the CD group, low iron stores may explain the prolonged PWd in our study group.
Both QT and QTc dispersion reflects inhomogeneity of ventricular repolarization and is used as a marker tendency for ventricular arrhythmia and sudden cardiac death. Previous studies have shown that increased QT and QTc dispersions are significantly correlated with the burden of ventricular premature contractions in children with structurally normal hearts $(22,23)$. Besides QT and QTc dispersions, prolonged QT interval is another ECG marker for malignant ventricular arrhythmia which reflects delayed heart repolarization. Corazza et al. (24) reported that 33\% of CD patients had prolonged QT interval. Similar to Corazza et al. (24), we found increased QT and QTC dispersions in children with CD.

Studies have shown that the last part of the T-wave represents the arrhythmogenic tendency for malignant ventricular arrhythmias (25). The interval between the 


\begin{tabular}{|c|c|c|c|}
\hline & $\begin{array}{l}\text { Patient group } \\
\text { Mean } \pm \text { SD } \\
\text { M (Q1-Q3) }\end{array}$ & $\begin{array}{l}\text { Control group } \\
\text { Mean } \pm \text { SD } \\
M(Q 1-Q 3)\end{array}$ & $\mathbf{p}$ \\
\hline QTmax (ms) & $\begin{array}{l}0.35 \pm 0.04 \\
0.34(0.32-0.36)\end{array}$ & $\begin{array}{l}0.34 \pm 0.03 \\
0.34(0.32-0.36)\end{array}$ & $0.075+$ \\
\hline QTmin (ms) & $\begin{array}{l}0.29 \pm 0.04 \\
0.28(0.26-0.32)\end{array}$ & $\begin{array}{l}0.32 \pm 0.04 \\
0.32(0.3-0.34)\end{array}$ & $<0.001+$ \\
\hline QTcmax (ms) & $\begin{array}{l}0.44 \pm 0.03 \\
0.43(0.42-0.45)\end{array}$ & $\begin{array}{l}0.42 \pm 0.02 \\
0.41(0.39-0.43)\end{array}$ & $<0.001+$ \\
\hline QTcmin (ms) & $\begin{array}{l}0.37 \pm 0.02 \\
0.39(0.37-0.40)\end{array}$ & $\begin{array}{l}0.39 \pm 0.02 \\
0.38(0.35-0.4)\end{array}$ & $<0.001^{*}$ \\
\hline QTdisp (ms) & $\begin{array}{l}0.06 \pm 0.02 \\
0.05(0.04-0.08)\end{array}$ & $\begin{array}{l}0.02 \pm 0.02 \\
0.02(0.02-0.03)\end{array}$ & $<0.001+$ \\
\hline Pmax (ms) & $\begin{array}{l}0.11 \pm 0.02 \\
0.1(0.09-0.12)\end{array}$ & $\begin{array}{l}0.1 \pm 0.02 \\
0.1(0.09-0.12)\end{array}$ & $0.834+$ \\
\hline Pmin (ms) & $\begin{array}{l}0.05 \pm 0.01 \\
0.06(0.04-0.06)\end{array}$ & $\begin{array}{l}0.06 \pm 0.01 \\
0.06(0.06-0.07)\end{array}$ & $0.015+$ \\
\hline Pdisp (ms) & $\begin{array}{l}0.05 \pm 0.02 \\
0.05(0.04-0.06)\end{array}$ & $\begin{array}{l}0.04 \pm 0.01 \\
0.04(0.04-0.06)\end{array}$ & $0.024+$ \\
\hline TP-emax (ms) & $\begin{array}{l}0.09 \pm 0.02 \\
0.09(0.08-0.1)\end{array}$ & $\begin{array}{l}0.09 \pm 0.02 \\
0.08(0.08-0.1)\end{array}$ & $0.151+$ \\
\hline TP-emin (ms) & $\begin{array}{l}0.05 \pm 0.01 \\
0.06(0.05-0.06)\end{array}$ & $\begin{array}{l}0.06 \pm 0.01 \\
0.06(0.05-0.06)\end{array}$ & $0.272+$ \\
\hline TP-edisp (ms) & $\begin{array}{l}0.04 \pm 0.01 \\
0.04(0.02-0.05)\end{array}$ & $\begin{array}{l}0.03 \pm 0.01 \\
0.03(0.02-0.04)\end{array}$ & $0.180+$ \\
\hline TP-e/QTmax & $\begin{array}{l}0.27 \pm 0.04 \\
0.27(0.24-0.28)\end{array}$ & $\begin{array}{l}0.26 \pm 0.04 \\
0.25(0.23-0.28)\end{array}$ & $0.378+$ \\
\hline TP-e/QTmin & $\begin{array}{l}0.19 \pm 0.03 \\
0.19(0.17-0.21)\end{array}$ & $\begin{array}{l}0.18 \pm 0.03 \\
0.18(0.15-0.2)\end{array}$ & $0.039 *$ \\
\hline TP-e/QTcmax & $\begin{array}{l}0.21 \pm 0.05 \\
0.20(0.18-0.24)\end{array}$ & $\begin{array}{l}0.21 \pm 0.04 \\
0.21(0.18-0.24)\end{array}$ & $0.297+$ \\
\hline TP-e/QTcmin & $\begin{array}{l}0.15 \pm 0.03 \\
0.16(0.13-0.17)\end{array}$ & $\begin{array}{l}0.15 \pm 0.03 \\
0.15(0.12-0.17)\end{array}$ & $0.162+$ \\
\hline $\mathrm{RR}$ (ms) & $\begin{array}{l}637.69 \pm 156.76 \\
630(500-742.5)\end{array}$ & $\begin{array}{l}691.61 \pm 138.51 \\
675(567.5-765)\end{array}$ & $0.031+$ \\
\hline LVEF\% & $\begin{array}{l}67.71 \pm 11.18 \\
68(64.5-73)\end{array}$ & $\begin{array}{l}69.58 \pm 6.18 \\
70(64.75-74)\end{array}$ & $0.738+$ \\
\hline
\end{tabular}

peak and the end of the T-wave (Tp-e interval) and Tp-e dispersion have emerged as novel ECG markers of increased dispersion of ventricular repolarization. These parameters are more useful markers than QT dispersion for TDR. Previous studies have shown prolonged Tp-e interval and Tp-e dispersion in long QT syndrome, Brugada syndrome, hypertrophic cardiomyopathy and myocardial infraction $(26,27)$. Unlike Tp-e interval, Tp-e/QT is not affected by heart rate and body weight; thus, it has been used as a more sensitive marker rather than Tp-e and QT intervals.
The Tp-e/QT ratio is an important index of arrhythmogenic tendency in acquired and congenital channelopathies (9). Demirtas et al. (10) showed that the Tp-e interval and Tp-e/QT ratio are higher in patients with CD compared to controls. Additionally, they reported significantly increased Tp-e/QT ratios in parallel to disease duration. Given that the Tp-e interval, Tp-e dispersion and Tp-e/QT ratio have not been evaluated in children with CD before, in the present study, we found prolonged Tp-e dispersion and increased Tp-e/QT ratios in children with CD. However, we could not 


\begin{tabular}{|c|c|c|c|c|}
\hline & $\begin{array}{l}\text { Seronegative under gluten free } \\
\text { diet } \\
\text { Mean } \pm \text { SD } \\
\text { M (Q1-Q3) }\end{array}$ & $\begin{array}{l}\text { Seropositive under gluten free } \\
\text { diet } \\
\text { Mean } \pm \text { SD } \\
\text { M (Q1-Q3) }\end{array}$ & $\begin{array}{l}\text { New diagnosis } \\
\text { Mean } \pm \text { SD } \\
\text { M (Q1-Q3) }\end{array}$ & $\mathbf{p}$ \\
\hline n (\%) & $23(44.2)$ & $13(25)$ & $16(30.8)$ & \\
\hline QTdisp (ms) & $\begin{array}{l}0.05 \pm 0.03 \\
0.05(0.04-0.08)\end{array}$ & $\begin{array}{l}0.06 \pm 0.03 \\
0.06(0.04-0.08)\end{array}$ & $\begin{array}{l}0.06 \pm 0.02 \\
0.05(0.04-0.08)\end{array}$ & $0.707+$ \\
\hline Pdisp (ms) & $\begin{array}{l}0.05 \pm 0.02 \\
0.05(0.04-0.06)\end{array}$ & $\begin{array}{l}0.06 \pm 0.02 \\
0.05(0.04-0.08)\end{array}$ & $\begin{array}{l}0.05 \pm 0.02 \\
0.05(0.04-0.06)\end{array}$ & $0.649 *$ \\
\hline TP-edisp (ms) & $\begin{array}{l}0.04 \pm 0.02 \\
0.04(0.02-0.05)\end{array}$ & $\begin{array}{l}0.04 \pm 0.01 \\
0.04(0.03-0.05)\end{array}$ & $\begin{array}{l}0.04 \pm 0.01 \\
0.03(0.02-0.04)\end{array}$ & $0,643+$ \\
\hline TP-e/QTmax & $\begin{array}{l}0.26 \pm 0.05 \\
0.26(0.25-0.28)\end{array}$ & $\begin{array}{l}0.27 \pm 0.05 \\
0.28(0.23-0.32)\end{array}$ & $\begin{array}{l}0.26 \pm 0.04 \\
0.27(0.24-0.29)\end{array}$ & $0.614+$ \\
\hline TP-e/QTmin & $\begin{array}{l}0.19 \pm 0.04 \\
0.19(0.16-0.21)\end{array}$ & $\begin{array}{l}0.2 \pm 0.04 \\
0.19(0.17-0.21)\end{array}$ & $\begin{array}{l}0.19 \pm 0.03 \\
0.19(0.17-0.21)\end{array}$ & $0.915+$ \\
\hline TP-e/QTcmax & $\begin{array}{l}0.22 \pm 0.05 \\
0.21(0.18-0.25)\end{array}$ & $\begin{array}{l}0.22 \pm 0.04 \\
0.21(0.18-0.26)\end{array}$ & $\begin{array}{l}0.19 \pm 0.04 \\
0.18(0.17-0.21)\end{array}$ & $0.187^{*}$ \\
\hline TP-e/QTcmin & $\begin{array}{l}0.16 \pm 0.03 \\
0.17(0.14-0.17)\end{array}$ & $\begin{array}{l}0.16 \pm 0.03 \\
0.16(0.13-0.17)\end{array}$ & $\begin{array}{l}0.14 \pm 0.02 \\
0.13(0.11-0.16)\end{array}$ & $0.115^{*}$ \\
\hline $\mathrm{RR}(\mathrm{ms})$ & $\begin{array}{l}676.96 \pm 147.54 \\
680(540-760)\end{array}$ & $\begin{array}{l}656.92 \pm 154.24 \\
700(510-750)\end{array}$ & $\begin{array}{l}565.63 \pm 156.12 \\
520(440-660)\end{array}$ & $0.079 *$ \\
\hline
\end{tabular}

+Kruskal-Wallis analysis, *One-Way ANOVA, Data are given as mean \pm SD, SD: Standard deviation, LVEF: Left ventricular ejection fraction, ms: Milliseconds, QTc: Corrected QT interval, TP-e: T peak to end

find any difference in terms of Tp-e interval, and we did not demonstrate any correlation between disease duration and these parameters. Additionally, when we compared the seropositive, seronegative patients practicing a gluten free diet and those patients with a new diagnosis, we did not find any difference between the groups in terms of ECG parameters. The short follow-up period may be the major reason for these results. Nutritional deficiency and autoimmune triggered myocardial involvement may have led to the increased QT, QTc and Tp-e dispersions and Tp-e/ QT ratio in our study. Furthermore, when seronegative patients with celiac diet were compared to controls, QT and QTC dispersions were significantly higher in the celiac patients. These results suggest that CD patients continue to have a cardiac risk despite diet and that autoimmunity may lead to this situation. Due to the lack of studies evaluating these ECG parameters in children with CD, our study may be the starting point for further electrophysiological studies to evaluate potentially fatal atrial and ventricular arrhythmias in this patient population.

\section{Study Limitations}

Our study has some limitations that need to be considered. First, its relatively small sample size is the foremost limitation of our study. Second, we could not evaluate the ventricular functions by strain echocardiography to demonstrate subclinical left ventricular dysfunction. Third, it is possible that we did not find any correlation between ECG parameters and disease duration due to the short follow-up period. Finally, we could not perform 24-hour ECG monitoring on patients with CD and evaluate future arrhythmic events.

\section{Conclusion}

Our study showed that CD is associated with changes in some ECG parameters such as prolonged PWd, QT, QTc and Tp-e dispersions and increased Tp-e/QT ratio, which are considered as predictors of atrial and ventricular arrhythmias in special populations. Due to the long-life expectancy in children, pediatric patients with $C D$ may be considered to be at risk of developing arrhythmias. For this reason, these parameters should be evaluated carefully in children with CD. Longer prospective electrophysiological studies are needed to demonstrate the long-term clinical and prognostic results of these ECG parameters.

\section{Ethics}

Ethics Committee Approval: The research procedure was approved by the Local Ethics Committee (no: 2018/3-9). 
Informed Consent: The patients signed consent forms which gave information concerning the purpose of this study.

Peer-review: Internally peer-reviewed.

\section{Authorship Contributions}

Concept: T.D., Data Collection or Processing: Y.Ç.A., B.A., Echocardiography: B.G., Writing: T.D., N.N., C.K., Critical Revision: M.B.

Conflict of Interest: No conflict of interest was declared by the authors.

Financial Disclosure: The authors declared that this study received no financial support.

\section{References}

1. Setty M, Hormaza L, Guandalini S. Celiac disease: risk assessment, diagnosis, and monitoring. Mol Diagn Ther 2008; 12:289-98.

2. Troncone R, Jabri B. Coeliac disease and gluten sensitivity. J Intern Med 2011; 269:582-90.

3. Dube C, Rostom A, Sy R, Cranney A, et al. The prevalence of celiac disease in average risk and at risk Western Europe an populations: a systematic review. Gastroenterology 2005; 128:57-67.

4. Katz KD, Rashtak S, Lahr BD, et al. Screening for celiac disease in a North American population: sequential serology and gastrointestinal symptoms. Am / Gastroenterol 2011; 106:13339.

5. Dalgic B, Sari S, Basturk B, et al. Turkish Celiac Study Group. Prevalence of celiac disease in healthy Turkish school children. Am J Gastroenterol 2011; 106:1512-7.

6. Ciaccio EJ, Lewis SK, Biviano AB, Iyer V, Garan H, Green PH. Cardiovascular involvement in celiac disease. World I Cardiol 2017; 9:652-66.

7. Deveci M, Aydoğan AU, Altun G, Kayabey Ö, Tuğral O, Babaoğlu $K$. Left ventricular mechanics are affected in children with celiac disease: A studybased on two-dimensional speckle tracking echocardiography Echocardiography 2017; 34:1339-46.

8. Dilaveris PE, Gialafos E), Sideris SK, et al. Simple electrocardiographic markers for the prediction of paroxysmal idiopathic atrial fibrillation. Am Heart / 1998; 135:733-8.

9. Gupta P, Patel $\mathrm{C}$, Patel $\mathrm{H}$, et al. T(p-e)/QT ratio as an index of arrhythmogenesis. J Electrocardiol 2008; 41:567-74.

10. Demirtas K, Yayla C, Yüksel M, et al. Tp-e interval and Tp-e/QT ratio in patients with celiac disease. Rev Clin Esp 2017; 8:439-45.

11. Kucukseymen $\mathrm{S}$, Cekin $\mathrm{AH}$, Bayar $\mathrm{N}$, et al. A novel biomarker for prediction of atrial fibrillation susceptibility in patients with celiac disease. PloS One 2018; 13:e0190382.

12. Husby S, Koletzko S, Korponay-Szabó IR, Mearin ML, Phillips A, Shamir R. European Society for pediatric gastroenterology, hepatology, and nutrition guidelines for the diagnosis of coeliac disease. J Pediatr Gastroenterol Nutr 2012; 54:136-60.

13. Rudski LG, Lai WW, Afilalo J, et al. Guidelines for the echocardiographic assessment of the right heart in adults: a report from the American Society of Echocardiography endorsed by the European Association of Echocardiography, a registered branch of the European Society of Cardiology, and the Canadian Society of Echocardiography. I Am Soc Echocardiogr 2010; 23:685-713.

14. Teichholz LE, Cohen MV, Sonnenblick EH, Gorlin R. Study of left ventricular geometry and function by B scan ultrasonography in patients with and without asynergy. N Engl I Med 1974; 291:12206.

15. Bazett $\mathrm{H}$. An analysis of the time-relations of electrocardiograms. Heart 1920; 7:353-70.

16. Curione M, Barbato M, Viola F, Francia P, De Biase L, Cucchiara S. Idiopathic dilated cardiomyopathy associated with coeliac disease: the effect of a gluten-freediet on cardiac performance. Dig Liver Dis 2002; 34:866-9.

17. Cohen J. Statistical power analysis for the behavioral sciences. 2nd ed. Hillsdale, NJ: Lawrence Erlbaum; 1988.

18. Frustaci A, Cuoco L, Chimenti C, et al. Celiac Disease Associated With Autoimmune Myocarditis. Circulation 2002; 105:2611-8.

19. Cenk S, Aylin DB, Fatma Ebru A, et al. Assessment of left ventricular function by strain-strain rate echocardiography in patients with celiac disease. Turk J Med Sci 2014; 44:173-7.

20. Karadas $U$, Eliaçik K, Baran M, et al. The subclinical effect of celiac disease on the heart and the effect of gluten-freediet on cardiac functions. Turk J Pediatr 2016; 58:241-5.

21. Karadeniz C, Özdemir R, Demirol M, et al. Low iron stores in otherwise healthy children affect electrocardiographic markers of Important cardiac events. Pediatr Cardiol 2017; 38:909-14.

22. Das BB, Sharma ). Repolarization abnormalities in children with a structurally normal heart and ventricular ectopy. Pediatr Cardiol 2004; 25:354-6.

23. Bluzaite I, Brazdzionyte J, Zaliunas R, Rickli H, Ammann P. QT dispersion and heart rate variability in sudden death risk stratification in patients with ischemic heart disease. Med Kaunas 2006; 42:450-4.

24. Corazza GR, Frisoni M, Filipponi C, Gullo L, Poggi VM, Gasbarrini G. Investigation of QT interval in adult coeliac disease. BMJ 1992; 304:1285.

25. Kors JA, Ritsemavan Eck HJ, Herpen G. The meaning of the tp-te interval and its diagnostic value. I Electrocardiol 2008; 41:57580.

26. Castro HJ, Antzelevitch C, Tornes BF, et al. Tpeak-tend and tpeak-tend dispersion as risk factors for ventricular tachycardia/ ventricular fibrillation in patients with the Brugada syndrome. I Am Coll Cardiol 2006; 47:1828-34.

27. Shimizu $M$, Ino $H$, Okeie $K$, et al. T-peak to T-end interval maybe a beter predictor of high-risk patients with hypertrophic cardiomyopathy associated with a cardiac troponin I mutation than QT dispersion. Clin Cardiol 2002; 25:335-9. 